\title{
Quantification of reduction in air pollution due to bypassing traffic in Delhi, India
}

\author{
Ch. Ravi Sekhar*, Niraj Sharma, Mukti Advani and Ravindra Kumar \\ Transportation Planning and Environment Division, CSIR-Central Road Research Institute, New Delhi 110 025, India
}

The worldwide known relationship between transport and air pollution is demanding innovative solutions for satisfying the mobility needs with minimum pollution. While reducing the mobility demand is a longterm target, the most commonly adopted approach is to decongest the 'hot spots' having an alarming level of pollution. The main objective of providing bypasses and expressways is to divert the through traffic coming into the city. Delhi is one of the most congested and polluted cities in India. Among the various sources, vehicular pollution is a significant source of air pollution. Different policies and strategies have been developed to decongest and depollute Delhi. The Eastern Peripheral Expressway (EPE) is one such option implemented to decongest the national capital of India by diverting the traffic not destined for Delhi. It becomes essential to evaluate the performance of such significant infrastructural investments for better decision making in the future. Accordingly, the present study quantifies the impact of constructed EPE in terms of diverted traffic and the reduction of vehicular pollution from the capital of India. For this, various primary surveys like classified traffic volume, origin-destination and fuel station surveys were conducted in the study area. Vehicle kilometre travelled for all vehicle types was calculated using the primary data, and this parameter is considered for quantifying vehicular emissions. The results showed that reduction of vehicular emission due to diverted traffic was $0.7 \%$ of PM $\left(\mathrm{PM}_{2.5}\right), 7.1 \%$ of $\mathrm{NO}_{x}$ and $2.5 \% \mathrm{CO}$ in the total vehicular emission load of Delhi.

Keywords: Air pollution, bypassing traffic, expressway, travel demand estimation, vehicular emission load.

ROAD infrastructure development in the form of new highways and expressways is always considered a sign of growth for any country. The main objective of the construction of bypass is to avoid the through traffic from the Central Business District (CBD) of a city. These bypass roads in the form of expressways are expected to improve the level of service (LOS), reduce journey time and traffic congestion in the bypassed area/city, along with environmental benefits in the form of reduced fuel consumption, and reduction in air and noise pollution.

*For correspondence. (e-mail: chalumuri.ravisekhar@gmail.com)
Bypasses do seem to reduce through traffic and help make places more attractive to investors and customers. Vitkūnas and Meidute ${ }^{1}$ have quantified the benefits in terms of reducing air pollution by the construction of a bypass in Vilnius city, Lithuania. The study concluded that to avoid the loss of travel time, the average speed on a bypass should be 1.6 times higher than taking the direct route. The study further observed that construction of the bypass not only reduced carbon monoxide emissions up to $35 \%$, but also resulted in less noise due to increased vehicular speed, increased fuel economy of vehicles and decreased traffic jams as well as travel time.

Increasing air pollution levels, particularly in the urban centres in most of the low- and middle-income countries with high population density, have become a global concern. From the literature, it was observed that $91 \%$ of the population resides in places where the air quality exceeds the World Health Organization (WHO) standards. WHO reported that air pollution has become a health risk with approximately 4.2 million deaths in a year and estimated that one out of every nine deaths resulted from air pollution $^{2,3}$. Dirgahayani ${ }^{4}$ examined the co-benefits by the introduction of a bus transportation system in the Greater Yogakartha city, Indonesia. The study quantified data from two sources that included vehicle quality improvement and avoided motorized trips. It concluded that reduction in $\mathrm{CO}_{2}$ emission could reach 77,769 tonnes within 14 years, if the buses were upgraded to CNG. Sun et al. ${ }^{5}$ compared the improvement effect of road construction with the substitution of metro rails. For this, they considered 28 cities having metro rail in China. The study concluded that in the long run, urban metro rail facility has a strong positive effect in reducing air pollution than road construction.

India being a rapidly growing economy, has seen a lot of economic and infrastructural activities, especially in terms of highway development in the past few years. However, the problem of deteriorating air quality has also become a significant cause of concern over the years. India loses around 3\% of its GDP due to air pollution ${ }^{6}$. Delhi, the capital city of India, is facing severe air pollution problems where air quality levels, particularly during winter months, exceed the National Ambient Air Quality Standards. Among the major contributing factors for increasing air pollution levels (including $\mathrm{PM}_{2.5}$ and $\mathrm{PM}_{10}$ concentrations) are motor vehicles operating in Delhi and 
its neighbouring areas (i.e. National Capital Region (NCR)). Delhi has been experiencing exponential growth in the number of motorized vehicles, which have increased from 4.3 million in 2005 to 10.7 million in 2018 (ref. 7). Delhi-registered vehicles constitute $4.22 \%$ of vehicles in India ${ }^{8}$. It is estimated that nearly $55 \%$ of the population ( 7.8 million people) in Delhi resides within $500 \mathrm{~m}$ of the roadside and is therefore at increased risk from traffic pollution". The Government of India (GoI) had taken various measures to control air pollution, particularly from the motor vehicles in Delhi. It included phasing-out of old vehicles, plying of 10-year diesel and 15-year petrol-driven vehicles in Delhi, environment compensation charge to regulate the entry of non-destined commercial vehicles into Delhi, odd-even policy, introduction of cleaner/alternate fuels like gaseous fuel (CNG, LPG, etc.), improved engine technology and compatible fuel; leapfrogging from BS-IV to BS-VI fuel standards by 1 April 2020, promotion of public transport and the metro network. Recently, GoI has notified the 'Commission for Air Quality Management for the National Capital Region and Adjoining Areas Ordinance, 2020' (ref. 10). This Commission is a statuary authority with powers to issue directions, take up complaints, restrict, regulate, prohibit and close any activity/industry that is likely to cause air pollution in NCR and adjoining areas. All these measures/policies included various action plans/strategies (short term, medium term and long term) by different stakeholders, including concerned Government agencies/ departments, in a time-bound manner. One of the noticeable features among the list of the measures taken up by GoI to control air pollution due to traffic is related to emphasizing the construction of peripheral bypasses to restrict the entry of non-destined vehicles to Delhi. Notably commercial vehicles which are not required to enter the city.

To decongest and depollute Delhi city, the Eastern Peripheral Expressway (EPE) was constructed and made operational in 2018 by diverting vehicular traffic which is not destined for Delhi to EPE. The EPE, also known as National Expressway (NE) II, is $135 \mathrm{~km}$ long. The six-lane expressway passes through the neighbouring states (viz. Haryana and Uttar Pradesh). The main objective of providing this infrastructure is to relieve traffic congestion in the neighbouring districts and reduce air pollution caused by the entry of non-destined commercial vehicles (mainly trucks) to Delhi. It was observed from the data that approximately 50,000 light and heavy trucks/commercial vehicles (excluding taxis) were entering Delhi through different entry points daily via peripheral expressways. These commercial vehicles were estimated to contribute about $30 \%$ of PM and $22 \%$ of $\mathrm{NO}_{x}$ load from the road transport sector in Delhi ${ }^{11}$.

The main objective of the present study is to estimate the improvement in air quality of Delhi in terms of savings in vehicular emission load due to diversion of non-destined traffic by the operation of EPE. For this, various traffic surveys were conducted at six interchanges on the identified study corridor to characterize the traffic and trip characteristics of different vehicles. A fuelstation survey was also carried out at nine different locations to identify the fuel usage type and category of the vehicles (agewise) plying on EPE. The collected primary data were used for estimating vehicular emission load saved by the diverted vehicles on EPE. The influence of traffic before EPE and business as usual was estimated using the widely employed vehicle kilometres travelled (VKT)-based emission factors. The emission factors for different categories of vehicles were considered from the Central Pollution Control Board (CPCB) guidelines ${ }^{12}$ to estimate emission load on bypassing (i.e. EPE) traffic.

\section{Study area and data collection}

\section{Physical characteristics of the study area}

Delhi, officially known as the National Capital Territory (NCT) of Delhi, had a population of about 16.8 million in 2011 (ref. 13), which is estimated to become 22 million (ref. 14). The city is located in India's northern region, having an area of 1484 sq. $\mathrm{km}$ and is the largest commercial centre of North India. Delhi also accounted for the highest vehicle registration of 8.8 million vehicles among million-plus cities of India in 2016 (ref. 8). The ingress of traffic from the nearby NCR towns also adds significant traffic congestion to Delhi. The present study focuses on the effect of the recently constructed EPE in terms of diverted traffic and, therefore, the reduction in vehicular pollution. EPE also passes through Haryana and Uttar Pradesh. It has six major grade-separated intersections (cloverleaf) with a closed tolling system, where the toll is collected based on the distance travelled by the motor vehicle at cloverleaf interchanges. Traffic data at all these locations were collected through a videography survey. Figure 1 presents the study area and location of six major intersections considered for detailed traffic data collection.

\section{Data collection}

In this study, both primary and secondary data were collected. Various traffic surveys were conducted at six cloverleaf interchanges on EPE and intersecting National Highways (NHs) and State Highways (SHs). Figure 1 shows the survey locations. The traffic surveys included classified traffic volume count survey, fuel-station surveys and origin-destination $(\mathrm{O}-\mathrm{D})$ surveys conducted at toll plazas.

These surveys were conducted on weekdays and weekends $(48 \mathrm{~h})$ to observe the traffic characteristics on the road network through a pre-designed survey format. 


\section{RESEARCH ARTICLES}

Classified turning movement traffic volume studies were conducted to understand the prevailing traffic volume on the NHs and diversion of traffic to EPE. Further, O-D surveys were conducted through a pre-designed questionnaire to retrieve travel information of passenger and goods vehicles. Fuel-station survey was also conducted in the vicinity of EPE to assess the age profile of various types of vehicles. Traffic surveys were conducted to determine the mode-wise traffic composition at the six identified interchanges on EPE and intersecting roads (NHs/SHs) using the videography survey method. Six different vehicle classifications, viz. bus/truck (two-axle), heavy motor vehicles (HMVs; three-axle), over-sized vehicles (seven axles and more), light motor vehicles (LMVs; car/jeep/taxi) and light commercial vehicles (LCVs; minibus/tempo) and other vehicles were considered.

The O-D survey was carried out in the area to estimate the extent of traffic demand from one zone to another and also determine the trip characteristics of the existing conditions of traffic using EPE. Travel-time data were collected by considering the Google Maps navigator for various possible trips on EPE. A summary of the journey time of trips was collected at three different time intervals. Before start of the journey, time was obtained from Google Maps navigation and compared with actual travel time. The journey time of vehicles using EPE and alternate roads (through the city) to reach the endpoint of EPE (Palwal) was compared.

Fuel-station surveys were carried out in the vicinity of the study area road network to identify the type of fuel

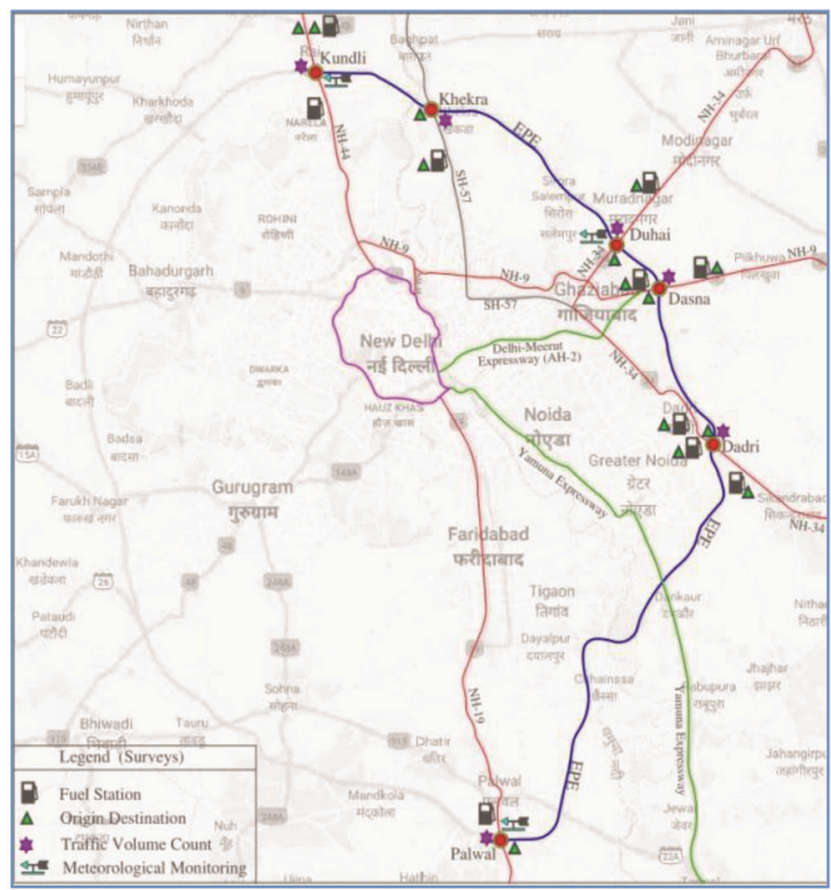

Figure 1. Study area and traffic survey locations.
(petrol/diesel/CNG), fuel-saving, amount and frequency of fuel-filling, mileage, type of engine, age profile and composition of fuel types (petrol, diesel, CNG) in total fleets. It was observed that $50 \%-70 \%$ of all vehicles passing on EPE were less than five-years-old. The fuel station and $\mathrm{O}-\mathrm{D}$ surveys were carried out to determine the percentage of fuel (e.g. petrol, diesel, CNG/LPG) used by different types of vehicles (viz. LCVs, trucks and buses) and also to make the classified traffic volume count data for each type and category of vehicles plying on each link of the EPE corridor, compatible with VKTbased emission factor data for different categories of vehicles provided by $\mathrm{CPCB}^{12}$.

\section{Traffic characteristics and estimation of traffic volume on links}

Figure $2 a$ shows the traffic composition at EPE. It is observed that LMVs were predominant (61\%), followed by HMVs $(13 \%)$ and LCVs $(6 \%)$. Figure $2 b$ shows the number of vehicles entering and exiting from EPE on a typical Sunday and Monday. It was observed that the maximum number of vehicles entering EPE was at Kundali. The number of vehicles entering at Kundali during weekdays and weekends was 10,488 and 9801 respectively.

From the vehicle count data (entering and exiting vehicles) at the six interchanges, the number of vehicles moving on a link (i.e. road segment connected by two interchanges) was calculated. This is required for estimating vehicular emissions, which are based on the number of vehicles and their travelled distances, i.e. VKT. Considering the number of vehicles entering and exiting from all six locations on EPE during the observed $48 \mathrm{~h}$ as productions and attractions of the origin-destination matrix provides O-D matrix for EPE (Table 1).

From the O-D matrix data, link volume can be calculated for all five road segments created by these six interchanges. This is an access-controlled bidirectional road with six entries and exits denoted as $i$ and $j$.

For calculating link volumes from the matrix of productions and attractions, the gravity model with
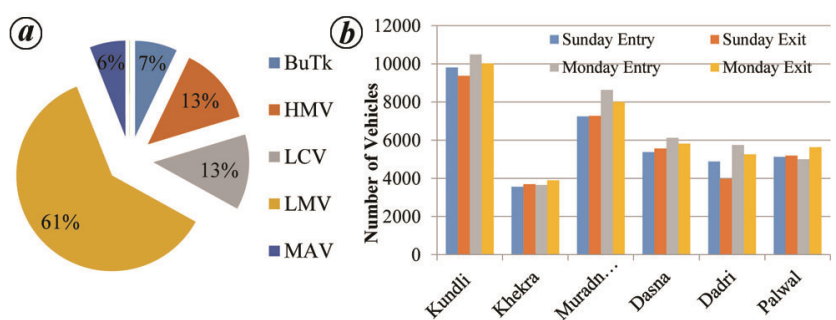

Figure 2. (a) Compositions of traffic and (b) total number of vehicles entering and exiting at six locations on Eastern Peripheral Expressway (EPE). 
RESEARCH ARTICLES

Table 1. Origin-destination matrix for six interchanges on Eastern Peripheral Expressway (EPE)

\begin{tabular}{lrrrrrrr}
\hline $\begin{array}{l}\text { Productions } \\
\text { (entering vehicles) }\end{array}$ & Kundli & Bagphat & Duhai & Dasna & Bilakpur & Palwal \\
\hline 9801 & 0 & 265 & 2783 & 2695 & 1982 & 2076 & Kundli \\
3554 & 243 & 0 & 846 & 883 & 726 & 855 & Bagphat \\
7248 & 2795 & 926 & 0 & 731 & 1032 & 1764 & Duhai \\
5366 & 2456 & 877 & 663 & 0 & 484 & 886 & Dasna \\
4881 & 2065 & 824 & 1070 & 553 & 0 & 369 & 0 \\
5123 & 1747 & 783 & 1478 & 817 & 298 & Bilakpur & Palwal \\
& 9307 & 3674 & 6841 & 5679 & 4523 & 5950 & Attractions (exiting vehicles) \\
\hline
\end{tabular}

Table 2. Estimated link volume (vehicles/day)

\begin{tabular}{llccc}
\hline Link no. & Connecting location & $\begin{array}{c}\text { Length of connecting } \\
\text { road link }(\mathrm{km})\end{array}$ & $\begin{array}{c}\text { Volume on a weekday } \\
(\text { vehicles/day; bidirectional) }\end{array}$ & $\begin{array}{c}\text { Volume on a weekend } \\
\text { (vehicles/day; bidirectional) }\end{array}$ \\
\hline 1 & Kundli-Khekra & 15.40 & $22,021\left(A\right.$ and $\left.A^{\prime}\right)$ & $19,886\left(A\right.$ and $\left.A^{\prime}\right)$ \\
2 & Khekra-Muradnagar & 29.20 & $28,765\left(B\right.$ and $\left.B^{\prime}\right)$ & $26,146\left(B\right.$ and $\left.B^{\prime}\right)$ \\
3 & Muradnagar-Dasna & 7.70 & $28,443\left(C\right.$ and $\left.C^{\prime}\right)$ & $25,533\left(C\right.$ and $\left.C^{\prime}\right)$ \\
4 & Dasna-Dadri & 20.60 & $22,552\left(D\right.$ and $\left.D^{\prime}\right)$ & $19,969\left(D\right.$ and $\left.D^{\prime}\right)$ \\
5 & Dadri-Palwa & 62.40 & $11,858\left(E\right.$ and $\left.E^{\prime}\right)$ & $12,142\left(E\right.$ and $\left.E^{\prime}\right)$ \\
\hline
\end{tabular}

Bidirectional $=$ Sum of link volume from node $i$ to $j$ and from node $j$ to $i$.

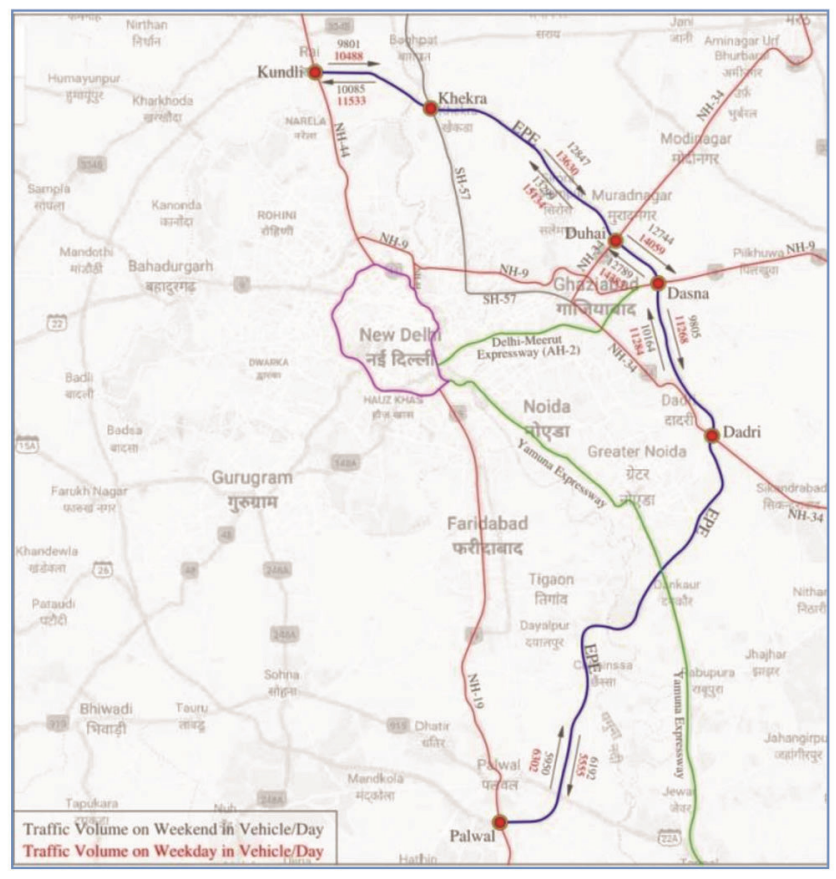

Figure 3. Link volume on a weekday and weekend.

impedance of the distance matrix was used. Link volume was calculated separately for each link (connected by $i$ and $j$ ) and each direction ( $i$ to $j$ and $j$ to $i$ ). Considering $n$ number of links (created by six interchanges) and nodes (interchanges) of each link as $i$ and $j, T_{i j}$ can be calculated. Productions at all nodes appearing before node $j$, traffic initiated at point $i$ but alighted before node $j$, and traffic moving in the reverse direction between all links before node $j$. Accordingly, eq. (1) was used for calculating trips on various links

$$
T_{n}(i-j)=\sum_{n=1}^{n=j}\left(P_{n}\right)-\sum_{j=j}^{i=j, i=1}\left(T_{j i}\right)-\sum_{i=1, j-1}^{j=i+1, j}\left(T_{j i}\right),
$$

where $n$ is the link created by nodes $i$ and $j, T_{n}(i-j)$ is the number of trips on link $n$ created by nodes $i$ and $j$ and $P_{n}$ is the production from node $i$ of the link connected with nodes $i$ and $j$.

Using eq. (1), link volume for all links, all directions, and for both the days was calculated. Table 2 and Figure 3 present the total traffic volume (bidirectional) for all five links for a weekday and weekend.

The O-D survey was carried out in the study area to estimate the extent of traffic demand from one zone to another and also to determine the trip characteristics of the existing conditions of traffic using EPE. Travel-time data were collected by considering the Google Maps navigator for various possible trips on EPE. A summary of the journey time of trips was collected at three different time intervals, viz. morning hours (8 am-10 am), afternoon hours $(2 \mathrm{pm}-4 \mathrm{pm})$ and evening hours $(8 \mathrm{pm}-$ $10 \mathrm{pm})$. The journey time was obtained from Google Navigator for all the three time intervals and this was considered as actual travel time. The journey time of vehicles using EPE and other roads (through the city) to reach the endpoint of EPE (Palwal) was compared. Figure 4 shows the distribution of journey time for the trip from Kundali (starting point) to Palwal (endpoint). It can be observed from the Figure 4, that trip time of commuters using EPE to reach Palwal is 119 min. Whereas trip time of commuter travelling through Delhi city roads (destined traffic) to Palwal is $161 \mathrm{~min}$. Thus, the average saving of journey time was estimated to be $43 \mathrm{~min}$. 


\section{Travel demand estimation}

Let us now focus on the origin and destination of all vehicles moving on EPE to understand how much it can prevent traffic from passing through the Delhi area.

\section{Development of travel demand model}

The travel demand model is a tool to assist in the development of the regional transportation plan and is useful in the policy decision-making process. The travel demand model utilizes a conventional four-step trip-based process consisting of trip generation, trip distribution, mode choice and traffic assignment. The model input variables include road network information, characteristics of each road link, origin and destination of traffic and spatial distribution. Secondary information required in the study area is the existing capacity and proposed capacity for the traffic demand model. To implement the four-stage travel demand model procedure, macroscopic simulation modelling is performed in VSIUM software ${ }^{15}$. The process of these four stages of the travel demand model is explained below.

The first stage in the travel demand model is trip generation. It establishes the relationship between trips produced and attracted between a given set of influencing parameters of the zone. For understanding the transport flows, the entire study area has been divided into smaller areas called traffic zones. In this study, the entire study area was divided into 17 zones based on the location of sites and consideration of existing physical infrastructure. The dependent variables in the trip generation model are trip production and attraction, starting from and ending in a particular zone respectively. The explanatory variable for the trip generation is population, number of households, number of earning members and household in a zone.

The next step of the travel demand model is trip distribution; it develops a matrix that displays the number of trips from each origin to each destination. In this study

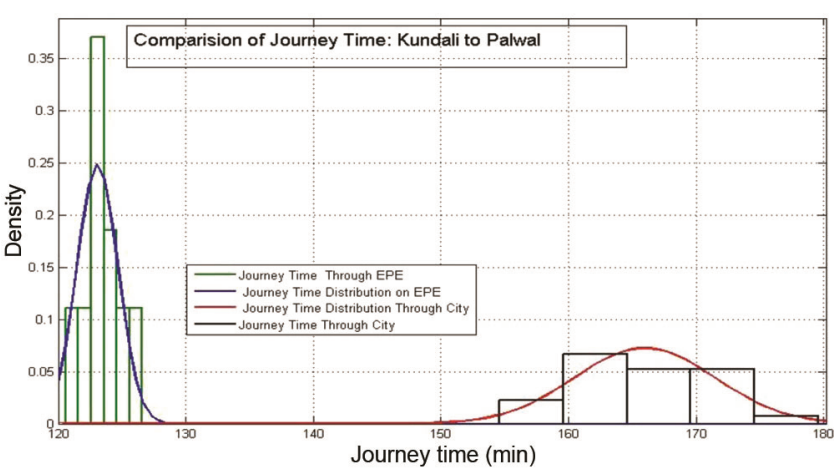

Figure 4. Compression of journey time distribution. the number of trips distributed between the 17 identified zones for all vehicles was estimated by performing $\mathrm{O}-\mathrm{D}$ survey at six different locations on the EPE for two days. The mode choice analysis describes how a commuter chooses his/her mode of travel. This plays a key role in policy making to any transportation system. Evaluation of the model split allows the modeller to determine what mode of transport will be used. In this study, mode split has been considered from the observed traffic composition obtained from traffic survey. The choice of private and commercial transport systems considered include car, bus, LCV, HMV and MAV.

The fourth stage of TDM is traffic assignment and this was done by using VISUM travel demand software. For this O-D trip matrix was considered as input for assigning the trips. For this, user equilibrium (UE) assignment method was considered. The equilibrium assignment distributes traffic demand according to Wardrop's first principle, which is 'every road user selects his route in such a way that the travel time on all alternate routes is the same, and that switching to a different route would increase personal travel time'. It is assumed that drivers are capable of correctly choosing their own shortest routes without accounting for the network-level benefits. Therefore, this study assumes that actual traffic on the network is close to the UE approach, as would be the case if most of the drivers are familiar with the road network and traffic conditions in the study area. Every driver is thus expected to minimize his/her travel time between an origin and destination pair by choosing the shortest route in terms of travel time.

The route search considers impedance, which results from the traffic volume of the previous step. Equilibrium assignment procedures update travel times iteratively based upon the link performance functions. A link performance function is a mathematical description of the travel time and link volume. The Bureau of Public Roads (BPR) function was used in the study as it is the most commonly used link performance function. This function relates link travel time as a function of the volume/ capacity ratio and is presented in eq. (2) below

$$
t=t_{\mathrm{a}}\left[1+\alpha\left(\frac{V}{C}\right)^{\beta}\right],
$$

Where $t$ is the link travel time $(\mathrm{min}), t_{\mathrm{a}}$ the free-flow travel time of link, $V$ the link volume $(\mathrm{pcu} / \mathrm{h}), C$ the link capacity $(\mathrm{pcu} / \mathrm{h})$ and $\alpha, \beta$ are calibration parameters.

Estimated peak hour traffic (vehicles/h) for the base year due to operations of various elements in the study area by considering the UE method is presented here. The developed traffic demand model was validated by comparing the observed traffic flow (traffic survey) and estimated traffic obtained by the travel demand model. 
Traffic assignment was carried out in PTV VISUM software for the base year, and link flow on each link was obtained as the output in terms of vehicle volume per day.

\section{Travel demand estimation for EPE}

The developed travel demand model was adopted for estimating traffic demand for the current year on the study road network and also on the NH connecting EPE. Figure $5 a$ and $b$ illustrates the flow of traffic in the 17 zones selected for a typical weekend and weekday respectively. The present study was conducted for two scenarios: (i) is when EPE exists and (ii) when EPE does not exist. Figure 6 presents assignment results for both the scenarios. Desire line diagrams show that maximum trip movement is between zone 9 and zone 7, i.e. between North Haryana and Delhi for both weekends and weekdays.

Scenario I - Traffic demand estimation when EPE exists: The present road network consists of the expressway, NHs, SHs and urban roads, and their assignment results are shown in Figure $6 a$ for a typical weekend and weekday respectively. From Figure $6 a$, it can be seen that maximum trip movement on EPE is between Murad Nagar and Dadri and between Kundli and Khekra, and maximum trip entry and exit on EPE is from Dadri, i.e. on NH-34, which is exiting from EPE towards Aligarh, Bulandshahr and Khujra. There is a slight increase in the link volume on a weekday compared to the weekend link volume.
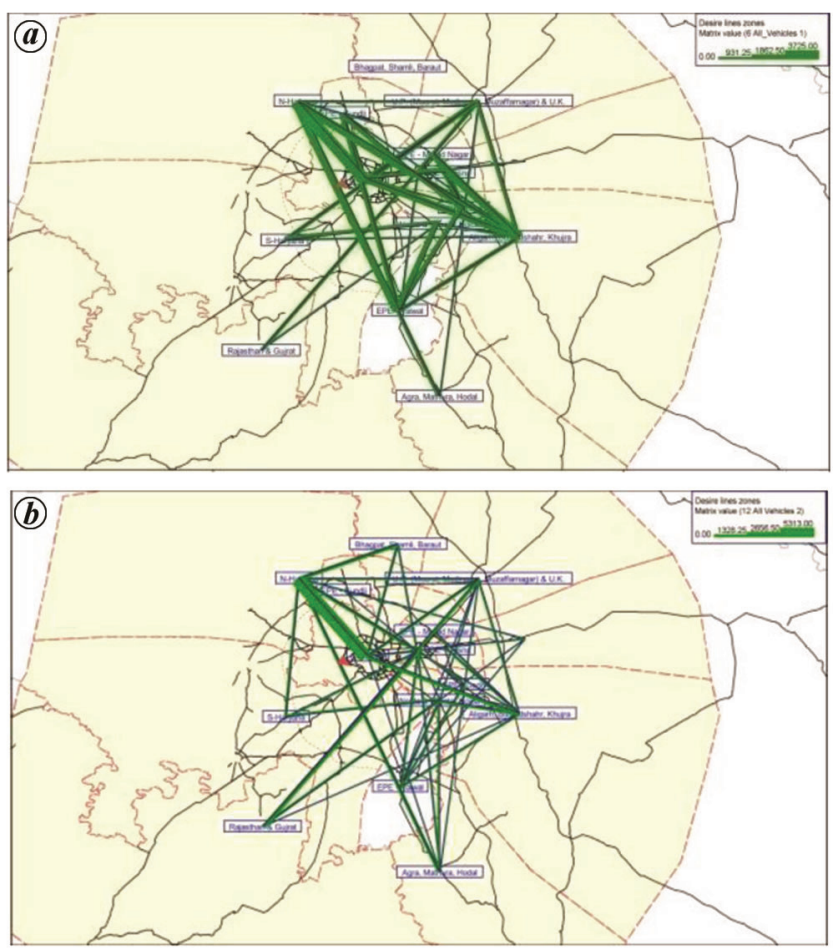

Figure 5. Desire line diagram for (a) weekends and (b) weekdays.
Scenario II - traffic demand estimation when EPE does not exist: The same procedure is adopted for this scenario also, and the assignment results are presented in Figure $6 b$ for a weekend and weekday respectively. The effect of the unavailability of EPE can be clearly seen from the assignment results as the assigned volume shows an increase on NH-44, NH-34 and NH-19 during both weekends and weekdays. The volume of traffic on the road links inside Delhi and Ghaziabad has also increased.

The traffic volume obtained on each link of EPE was considered for emission load quantification.

\section{Vehicular emission load quantification}

\section{Input variables}

Vehicle emissions saved due to diversion of traffic on the EPE expressed in terms of emission load estimation (kg/day or tonne/years) were estimated using VKT-based emission factors (EFs) for different vehicle categories. Table 3 shows EF for different vehicles categories ${ }^{12}$. VKT (expressed in terms of $\mathrm{g} / \mathrm{km}$ ) has been considered as activity data to determine emissions in terms of various pollutants, viz. $\mathrm{CO}$, hydrocarbons $(\mathrm{HC}), \mathrm{NO}_{x}, \mathrm{PM}$ and $\mathrm{CO}_{2}$. Further, deterioration factor (DF) for different types and categories of vehicles, indicating the effect on the ageing of the vehicles, was also considered in vehicle load estimation ${ }^{12}$. Table 4 shows the input data required and used in the present study to estimate vehicular emission load saved due to bypassing traffic on EPE.

\section{Vehicular emission load estimation}

The traffic data in the form of hourly classified traffic volume data on each link for both weekday and weekend traffic were grouped in different age groups (e.g. 200005, 2005-10, 2010-15, 2015-20) to make them compatible with EFs as indicated by $\mathrm{CPCB}^{12}$. They were further combined/grouped with the DFs for various categories of petrol and diesel vehicles according to their corresponding vehicle-age profiling ${ }^{16}$.

The vehicular emission load ( $p$ expressed in terms of tonne/day) on the EPE, which is equal to the vehicular emission load saved due to construction of the EPE (which is bypassing the non-destined traffic to Delhi) was estimated using eq. (3) below.

$$
\begin{aligned}
& P(i, y)=\sum_{j=1}^{j} N\left(j, k_{y}\right) \times L \times \operatorname{EF}\left(i, j, k_{y}\right) \\
& \times \operatorname{DF}\left(i, j, k_{y}\right) \times 10^{-6}(j) \sum\left(k_{y}\right),
\end{aligned}
$$

where $i$ is the pollutant $\left(\mathrm{CO}, \mathrm{HC}, \mathrm{PM}, \mathrm{NO}_{x}, \mathrm{CO}_{2}\right), j$ the type of vehicle (i.e. $2 \mathrm{~W}, 3 \mathrm{~W}, 4 \mathrm{~W}$, bus, truck), $k_{y}$ the age 


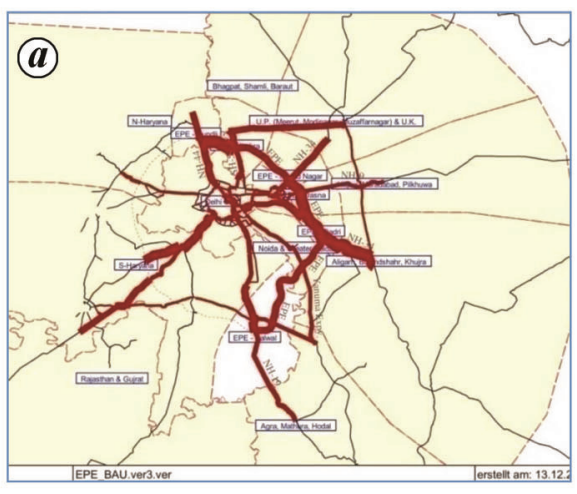

Weekend

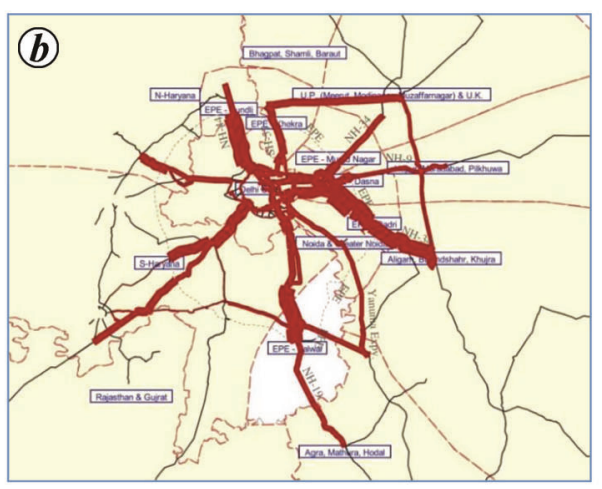

Weekend

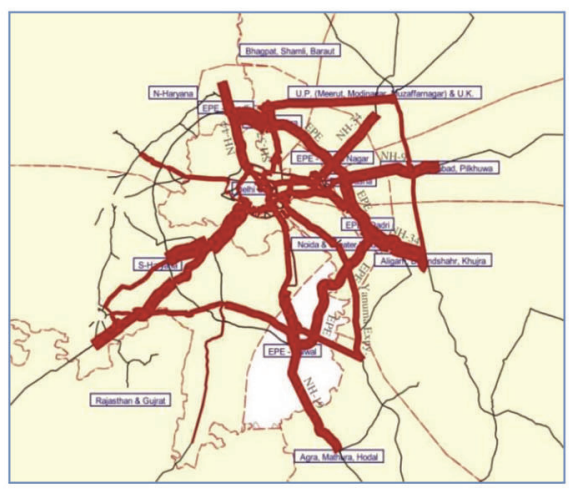

Weekday

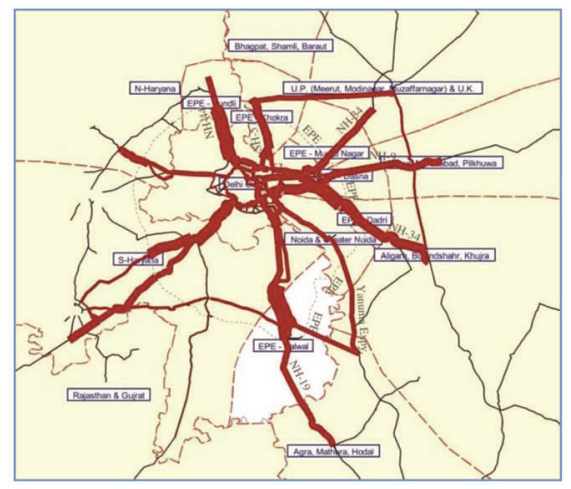

Weekday

Figure 6. Traffic assignment results when (a) EPE exists and (b) EPE does not exist.

Table 3. Emission factors for different vehicle categories ${ }^{12}$

\begin{tabular}{|c|c|c|c|c|c|c|c|}
\hline Type & Engine capacity (cc) & Year & $\mathrm{CO}(\mathrm{g} / \mathrm{km})$ & $\begin{array}{c}\mathrm{HC} \\
(\mathrm{g} / \mathrm{km})\end{array}$ & $\begin{array}{c}\mathrm{NO}_{x} \\
(\mathrm{~g} / \mathrm{km})\end{array}$ & $\begin{array}{c}\mathrm{PM} \\
(\mathrm{g} / \mathrm{km})\end{array}$ & $\mathrm{CO}_{2}(\mathrm{~g} / \mathrm{km})$ \\
\hline 3W CNG OEM (four-stroke) & $<200$ & Post 2000 & 1 & 0.26 & 0.5 & 0.015 & 77.7 \\
\hline Passenger cars (LPG) & $1000-1400$ & Post 2000 & 0.6 & 0.36 & 0.01 & 0.002 & 131.19 \\
\hline \multirow[t]{2}{*}{ Passenger cars (diesel) } & $<1600$ & 2001-05 BSII & 0.3 & 0.26 & 0.49 & 0.06 & 156.76 \\
\hline & & 2005-10 BSIII & 0.06 & 0.08 & 0.28 & 0.015 & 148.76 \\
\hline \multirow[t]{3}{*}{ Passenger cars (petrol) } & $1000-1400$ & 2001-05 BSII & 3.01 & 0.19 & 0.12 & 0.006 & 126.5 \\
\hline & & 2005-10 BSIII & 1.945 & 0.095 & 0.054 & 0.003 & 126.5 \\
\hline & & 2010-15 BSIV & 1.294 & 0.095 & 0.064 & 0.002 & 126.5 \\
\hline \multirow[t]{2}{*}{ Bus (CNG) } & $>6000$ & Post 2000 & 3.72 & 3.75 & 6.21 & 0.044 & 806.5 \\
\hline & & Post 2010 & 3.72 & 3.75 & 4.347 & 0.035 & 806.5 \\
\hline Bus (diesel) & & 2011-16 BSIV & 2.838 & 0.112 & 4.571 & 0.051 & 602.01 \\
\hline \multirow[t]{3}{*}{ HCV (diesel truck) } & $>6000$ & >2001 BSII & 6 & 0.37 & 9.3 & 1.24 & 762.39 \\
\hline & & BSIII & 6 & 0.37 & 8.63 & 0.42 & 762.39 \\
\hline & & BSIV & 4.345 & 0.259 & 6.041 & 0.071 & 762.39 \\
\hline \multirow[t]{4}{*}{ LCV (diesel) } & $>3000$ & BS I & 3.66 & 1.35 & 2.12 & 0.475 & 401.25 \\
\hline & & 2001-05 BSII & 3.66 & 1.35 & 2.12 & 0.475 & 401.25 \\
\hline & & 2006-10 BSIII & 3.66 & 1.35 & 2.12 & 0.475 & 401.25 \\
\hline & & 2011-15 BSIV & 2.65 & 0.946 & 1.484 & 0.137 & 401.25 \\
\hline \multirow[t]{2}{*}{ LCV (CNG) } & & $2006-10$ & 3.2 & & & 0.026 & \\
\hline & & $2011-15$ & 3.2 & & & 0.026 & \\
\hline
\end{tabular}


RESEARCH ARTICLES

Table 4. Input data considered for vehicular emission load estimation

\begin{tabular}{|c|c|c|}
\hline Parameters & Unit/value & Source/survey \\
\hline Length of each link (road sections of EPE; viz. links 1-5; Table 2) & $\mathrm{km}$ & Google maps \\
\hline $\begin{array}{l}\text { Classified traffic volume }(24 \mathrm{~h}) \text { on each link (different types and } \\
\text { categories plying on that particular link; weekdays and weekends) }\end{array}$ & No. of vehicles/h & $\begin{array}{l}\text { - Classified traffic volume } \\
\text { - Primary (closed-circuit television camera) and } \\
\text { manual/traffic count surveys on EPE }\end{array}$ \\
\hline $\begin{array}{l}\text { Age profile/vintage of a vehicle for the categorization of vehicles } \\
\text { plying on each link of EPE based on: } \\
\text { - Fuel type (petrol, diesel, CNG, LPG) } \\
\text { - Year of registration (to make the data compatible with (VKT-based) } \\
\text { emission factor data) }\end{array}$ & Number & $\begin{array}{l}\text { Primary (fuel station and origin-destination } \\
\text { surveys) }\end{array}$ \\
\hline $\begin{array}{l}\text { Emission factor (EF; VKT-based) for different types and categories of } \\
\text { vehicles (in terms of } \mathrm{CO}, \mathrm{HC}, \mathrm{NO}_{x}, \mathrm{PM} \text { and } \mathrm{CO}_{2} \text { ) }\end{array}$ & $\mathrm{g} / \mathrm{km}$ & Secondary ${ }^{12}$ \\
\hline $\begin{array}{l}\text { Deterioration factor (DF) for different types of vehicles (based on age } \\
\text { of the vehicles and type of pollutants emitted from them) }\end{array}$ & Factor $(\geq 1)$ & Secondary ${ }^{16}$ \\
\hline
\end{tabular}
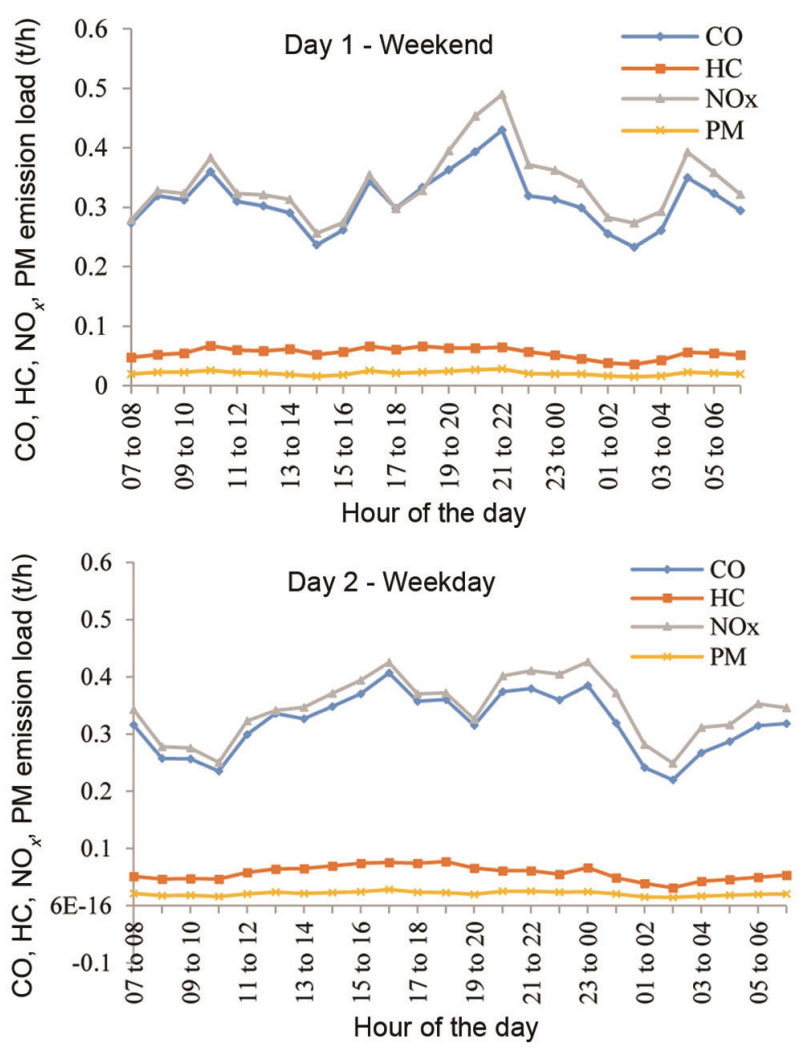

Figure 7. Diurnal variation of various pollutants contributing towards total vehicular emission load.

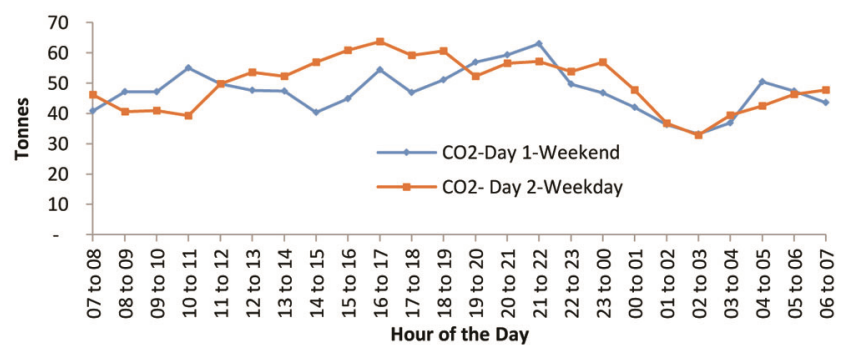

Figure 8. Diurnal variation of $\mathrm{CO}_{2}$ emission load. of vehicle in year $y, L$ the length of the highway/road corridor $(\mathrm{km})$, EF $\left(i, j, k_{y}\right)$ the emission factor for component $i$ in the vehicle type $j$ and age $k_{y}$ in year $y(\mathrm{~g} / \mathrm{km})$, $\mathrm{DF}\left(i, j, k_{y}\right)$ is the deterioration factor for component $i$ in the vehicle type $j$ and age $k_{y}$ in year $y$ (dimensionless) and $N$ is the number of vehicles.

As already mentioned, vehicular emission load from vehicular traffic plying on the EPE was also estimated for two days, viz. Sunday (weekend) and Monday (weekday). The diurnal variation in vehicular emission load (in terms of $\mathrm{CO}, \mathrm{HC}, \mathrm{NO}_{x}, \mathrm{PM}$ and $\mathrm{CO}_{2}$ ) during the weekend and weekday is shown in Figures 7 and 8 respectively.

Among the various pollutants, contribution of carbon dioxide emissions was estimated to be the highest compared to other pollutants (viz. $\mathrm{CO}, \mathrm{HC}, \mathrm{NO}_{x}, \mathrm{PM}$ ) during both the days. $\mathrm{CO}_{2}$ is one of the end-products of the combustion process and is not considered as a pollutant. It is emitted in considerable amounts from vehicles and being a prime greenhouse gas, becomes significant in emission studies. However, because of its large quantity compared to other pollutants, it was not combined with them. The vehicle category-wise contribution to total vehicular emission load (combining all pollutants, viz. CO, HC, $\mathrm{NO}_{x}$, PM but excluding $\mathrm{CO}_{2}$ ) was estimated on EPE (Figure 9). Further, commercial goods vehicles, viz. HMVs (three axles), MAVs (4-6 axles; 28\%) and buses/ trucks (two axles; $\sim 19 \%$ ) were the major contributors of total emission load, followed by HMVs (three axles; $\sim 18 \%)$ and LMVs/cars/vans/taxis $(\sim 17 \%)$ on weekends MAVs (4-6 axles; 28\%) and HMVs (3 axles; $\sim 22 \%$ ), were the major contributors of total vehicular emission load followed by buses/trucks (two axles; 20\%) and LMVs/cars/van/taxis ( $18 \%)$ on weekdays (Figure 10). It is pertinent to mention that apart from various categories of commercial vehicles, buses and taxis, no other categories of vehicles, viz. two-wheelers, threewheelers or non-motorized traffic (bullock cart, rickshaws) are allowed on the EPE according to expressway driving rule policy. 
Table 5. Reduction of pollution load on NCT Delhi road network due to EPE

\begin{tabular}{lccc}
\hline Pollutant & $\begin{array}{c}\text { Total vehicular emission load } \\
\text { (tonnes/day) in Delhi* }\end{array}$ & $\begin{array}{c}\text { Total vehicular emission load (tonnes/day) } \\
\text { avoided in Delhi due to EPE }\end{array}$ & $\begin{array}{c}\text { Emission load saved in Delhi due to bypassing of } \\
\text { traffic on EPE (\%) }\end{array}$ \\
\hline $\mathrm{PM}_{2.5} * *$ & 116.2 & 1.0 & 0.9 \\
$\mathrm{NO}_{x}$ & 113.4 & 8.0 & 7.1 \\
$\mathrm{CO}$ & 322.4 & 8.0 & 2.5 \\
\hline
\end{tabular}

*IIT Kanpur study for Delhi ${ }^{11}$. ** $\mathrm{PM}_{2.5}$, PM for emissions from vehicles.
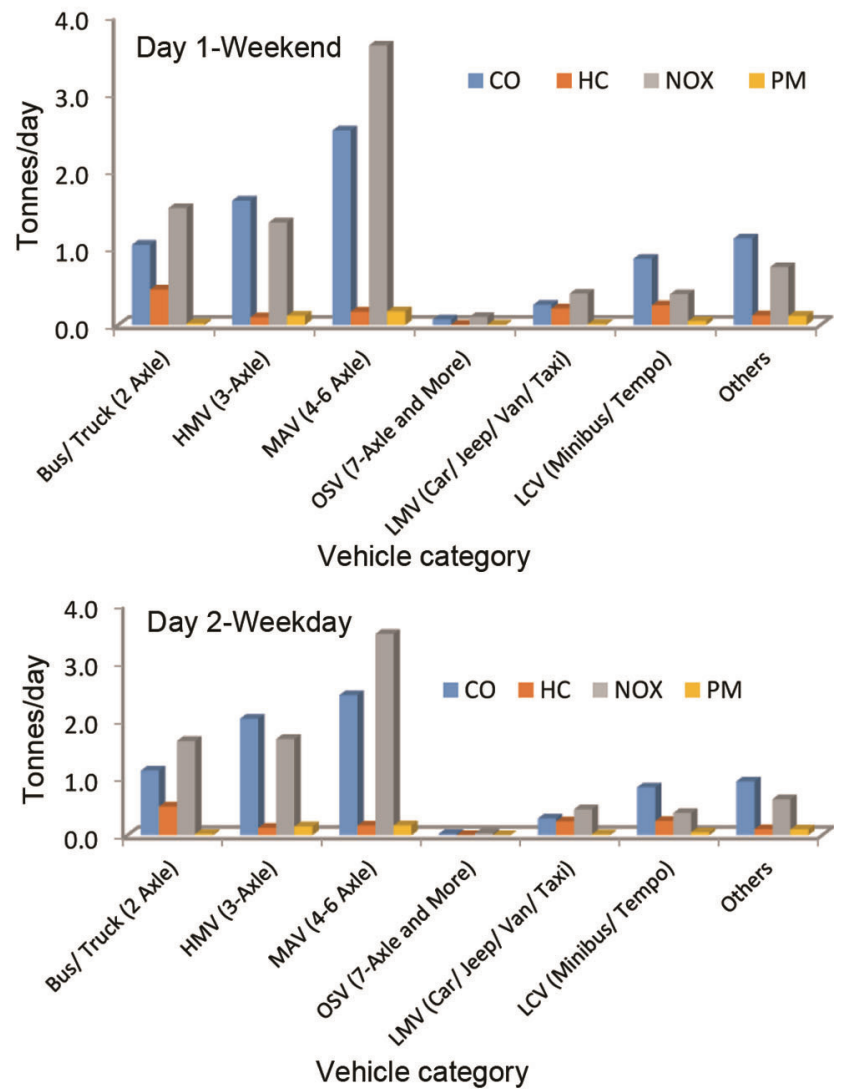

Figure 9. Vehicle category-wise emission load estimation.

Figure 11 shows the total vehicular emission load, combined for all vehicle categories plying on the EPE for various pollutants during weekends and weekdays. It shows that the highest contribution is from $\mathrm{NO}_{x}$, followed by $\mathrm{CO}, \mathrm{HC}$ and $\mathrm{PM}$ for both weekends and weekdays. However, no significant difference in terms of absolute values of respective pollutants was observed during both days.

Table 4 summarizes the reduction in vehicular emission load (in terms of $\mathrm{PM}_{2.5}, \mathrm{NO}_{x}$ and $\mathrm{CO}$ ) in Delhi due to EPE by avoiding non-destined traffic to the city and bypassing through EPE. The total estimated vehicular emission load in Delhi from an earlier study done by IIT Kanpur for the Department of Environment, GNCT Delhi ${ }^{11}$ was considered as the reference value. From Table 5 it is evident that the maximum reduction in terms of vehicular emission load is observed for $\mathrm{NO}_{x}(7.1 \%)$, followed by
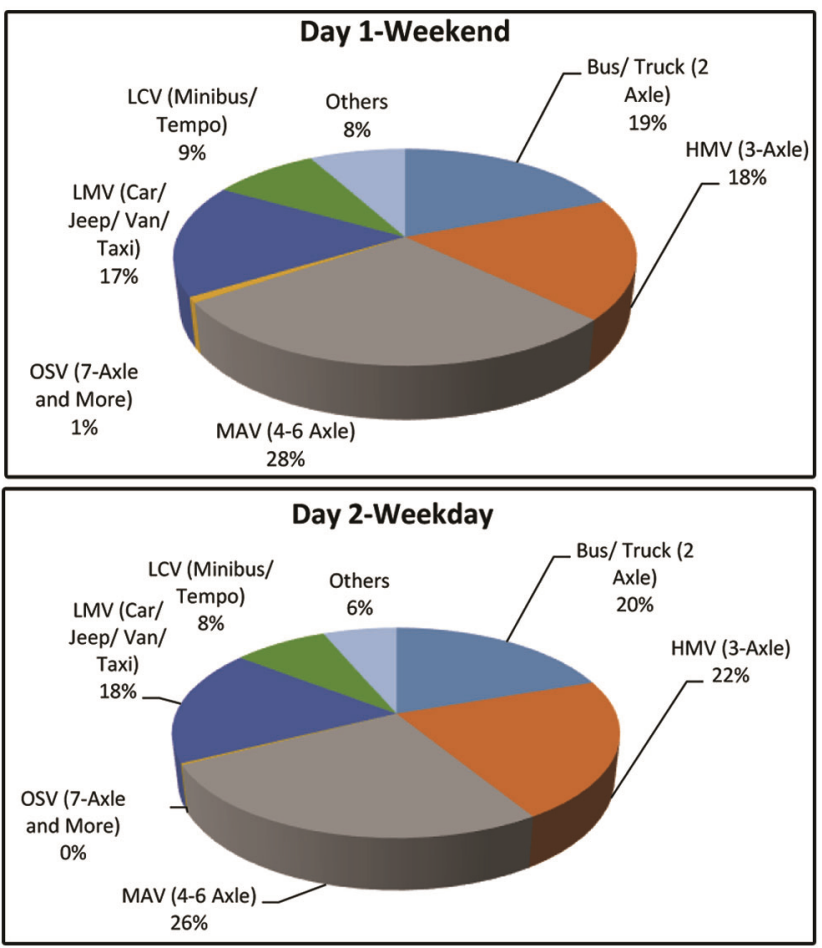

Figure 10. Contribution by different categories of vehicles to total emission load.

CO $(2.5 \%)$ and PM (0.9\%). This reduction may be minimal $(1 \%-3 \%)$ when the total air pollution load in Delhi from all the sources (including vehicular and other sources such as industry, etc.) is considered. However, with the completion of the Western Peripheral Expressway (WPE, completing the whole bypass road of $270 \mathrm{~km}$ ) and with gradual increase in the EPE (combined with WPE) traffic, the total vehicular emission load as well as total air pollution load in Delhi are expected to decrease significantly in future. The construction of EPE will further reduce the idling fuel consumption and corresponding emissions in Delhi, as a significant number of nondestined motor vehicles will not be entering into the city. As a result, a vehicle will not face various stoppages (stop and go operation during idling) at traffic signals in the city limits. Idling emissions have been identified as one of the major contributors to the deterioration of air quality in Delhi, particularly at signalized traffic intersections $^{17}$. 
RESEARCH ARTICLES

Table 6. Volume $(V)$-Capacity $(C)$ ratio on cross roads (National Highways (NHs)/State Highways (SHs))

\begin{tabular}{|c|c|c|c|c|c|c|}
\hline Cross road & \multicolumn{2}{|c|}{ If, no EPE is available } & \multicolumn{2}{|c|}{ If EPE is available } & \multicolumn{2}{|c|}{ Difference of $V / C$ ratio on crossroads } \\
\hline On NH-44, near Kundli & 0.97 & 0.91 & 0.83 & 0.79 & 0.14 & 0.12 \\
\hline On SH-57, near Khekra & 0.35 & 0.28 & 0.28 & 0.23 & 0.07 & 0.05 \\
\hline On NH-34, near Murad Nagar & 0.84 & 0.90 & 0.79 & 0.80 & 0.05 & 0.10 \\
\hline On NH-9, near Dasna & 0.82 & 0.83 & 0.75 & 0.77 & 0.07 & 0.06 \\
\hline
\end{tabular}
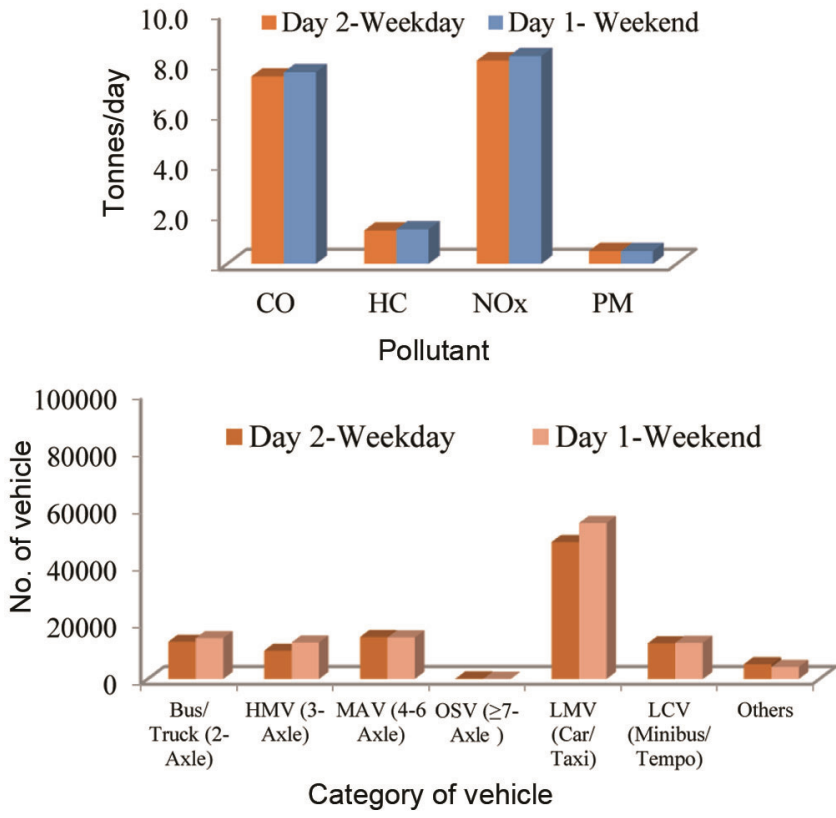

Figure 11. Total emission load and corresponding traffic volume on weekends and weekdays.

\section{Performance evaluation}

Performance evaluation of the studied road network was done considering the $\mathrm{V} / \mathrm{C}$ ratio. The peak-hour traffic volume of each road obtained from the field traffic volume was considered as volume $(V)$ of the road. The capacity $(C)$ of each road was chosen considered from the Indian Highway Capacity Guidelines ${ }^{18}$. The study road network has been classified based on their function of road such as arterial, sub-arterial and collector streets and the number lanes of each road were considered for estimating the capacity ${ }^{18}$. For the two scenarios, viz. no EPE is available, and EPE is available, the $V / C$ ratio was determined using field data for the base year and compared to evaluate the performance of EPE (Table 6). With no EPE, the $V / C$ ratio varied from 0.35 to 0.97 for weekends and 0.28 to 0.91 for weekdays. If EPE exists, the $V / C$ ratio varied from 0.28 to 0.83 and 0.23 to 0.80 for weekends and weekdays respectively. The average benefit of EPE is measured in terms of volume $(V)$ to capacity $(C)$ ratio in the studied road network (crossroads of EPE) due to the existence of EPE which was estimated to be 0.1 for both weekdays and weekends. The average speed of vehicles travelling from Kundali to Palwal using the EPE corridor was $68 \mathrm{~km} / \mathrm{h}$, whereas the average speed of vehicles travelling through the city using arterial roads was $39 \mathrm{~km} / \mathrm{h}$.

\section{Conclusion}

Construction of bypasses reduces through traffic and helps in reducing traffic congestion and air pollution. The present study quantified the reduction of air pollution levels due to bypassing vehicular traffic on EPE. Primary data, including traffic volume, origin and destination, and fuel station data were collected. The travel demand model was developed to simulate the travel pattern of traffic volume on EPE and compared with a real-world scenario. The major inferences drawn from traffic analysis were that the entry traffic volume varied from 3650 to 10,488 vehicles/day on weekdays at various locations of EPE. Similarly, the exit traffic volume varied from 3885 to 16,257 vehicles/day on different exits of EPE.

The maximum entry of traffic volume $(10,488$ vehicles/day) was observed at Kundli and the maximum exit of traffic volume (16,257 vehicles/day) was observed at Dadri. Maximum peak hour flow was observed during evening hours at all the study locations. From the traffic composition, it was observed that LMV traffic (cars, vans and jeeps) were predominant $(61 \%)$, followed by MMOs (13\%), LMVs, MAVs and OSVs (6\% each) on EPE. The maximum diversion of traffic (14.21\%) from SH-57 (near Khekra) to EPE was observed during weekdays and minimum diversion of traffic (7\%) from NH-9 (near Dasna) to EPE was found during weekdays.

An average saving of journey time of about 45 min was estimated due to the operation of EPE. A comparative evaluation of the performance of the transportation system due to EPE was done. The analysis revealed that the existence of EPE benefit on surrounding road network was measured interims of $V / C$ and it was observed that the $V / C$ value was reduced by 0.1 for both weekdays and weekends. The reduction of vehicular emission load due to EPE was estimated in terms of $\mathrm{PM}_{2.5}, \mathrm{NO}_{x}$ and $\mathrm{CO}$, and was found to be $0.90,7.1$ and 2.5 tonnes/day respectively, 
for the base year traffic volume. This is about $0.9 \%$ $\left(\mathrm{PM}_{2.5}\right), 7.1 \%\left(\mathrm{NO}_{x}\right)$ and $2.5 \%(\mathrm{CO})$ reduction in terms of total vehicular emission load contributed by motor vehicles in Delhi.

1. Vitkūnas, R. and Meidute, I., Evaluation of bypass influence on reducing air pollution in Vilnius city. Transport, 2011, 26(1), 4349; doi:10.3846/16484142.2011.561004.

2. WHO, Ambient air pollution: a global assessment of exposure and burden of disease, World Health Organization, Geneva, Switzerland, 2016.

3. WHO, Air pollution and health: Summary, World Health Organization, Geneva, Switzerland, 2019; https://www.who.int/ airpollutionambient/about/en/ (accessed on 24 July 2019).

4. Dirgahayani, P., Environmental co-benefits of public transportation improvement initiative: the case of Trans-Jogja bus system in Yogyakarta, Indonesia. J. Clean. Prod., 2013, 58, 74-81.

5. Sun, C., Zhang, W., Luo, Y. and $\mathrm{Xu}, \mathrm{Y}$., The improvement and substitution effect of transportation infrastructure on air quality: an empirical evidence from China's rail transit construction. Energy Policy, 2019, 129, 949-957.

6. Dahiya, S., Myllyvirta, L. and Sivalingam, N., Airpocalypse: assessment of air pollution in Indian cities. Greenpeace Clean Air Nation. Green Peace Environment Trust, 2017.

7. Economic Survey of Delhi, Government of National Capital Territory of Delhi, 2019.

8. MoRTH, Road Transport Yearbook (2015-16), Ministry of Road Transport and Highways, GoI, 2018.

9. Jerrett, M. et al., Automobile traffic around the home and attained body mass index: a longitudinal cohort study of children aged 10-18 years. Prev. Med., 2010, 50, S50-S58 (PubMed: 19850068).

10. The Commission for Air Quality Management in National Capital Region and Adjoining Areas (GOI Ordinance 2020).

11. IITK, Comprehensive study on air pollution and greenhouse gases (GHGs) in Delhi (Final report: air pollution component). Prepared by IIT Kanpur for the Department of Environment, Government of the National Capital Territory of Delhi and Delhi Pollution Control Committee, IIT Kanpur, 2016.

12. CPCB, Status of pollution generated from road transport in six mega cities. Central Pollution Control Board, Ministry of Environment, Forest and Climate Change, Government of India (GoI), 2015; http://cpcb.nic.in/cpcbold/upload/NewItems/NewItem 215_Report_Status_RoadTransport_SixCities.pdf

13. Census of India 2011: Rural Urban Distribution of Population. Registrar General of India, New Delhi, India; http://www. censusindia.gov.in/2011census/population_enumeration.html (accessed 5 July 2014).

14. Master Plan for Delhi, Delhi Development Authority, New Delhi, 2021; https://dda.org.in/tendernotices_docs/may1/MPD-2021_ 31.03.2017260417.pdf

15. PTV VISUM (Planung Transport Verkehr AG) Visum 12 Software and User Manual. PTV, Karlsruhe, Germany, 2011.

16. CPCB, Transportation fuel quality for year 2005. PROBES/ 78/2000-01, Central Pollution Control Board, Ministry of Environment and Forests, GoI, 2000.

17. Sharma, N., Kumar, P. V., Kumar, P., Singh, A., Dhyani, R., Sekhar, C. R. and Ravinder, K., Measurement of idling fuel consumption and estimation of emission at selected signalized intersections in Delhi. J. Clean. Prod., 2019, 212, 8-19.

18. Indo-HCM, Indian Highway Capacity Manual, CSIR-Central Road Research Institute, New Delhi, 2017.

ACKNOWLEDGEMENTS. We acknowledge that the data considered for this paper was collected as part of the study entitled 'Quantification of the reduction of air pollution level due to bypassing vehicular traffic on Eastern Expressway (EPE)', sponsored by the Department of Environment, Government of NCT of Delhi.

Received 24 August 2020; revised accepted 19 January 2021

doi: $10.18520 / \mathrm{cs} / \mathrm{v} 120 / \mathrm{i} 10 / 1600-1610$ 